\title{
Fertirrigação com dejetos de suínos: uma análise de custos do sistema autopropelido $\mathrm{x}$ sistema tratorizado
}

\author{
Ana Claudia Machado Padilha* \\ Denise Carvalho Tatim** \\ Eduardo Conterato Tres**** \\ Marcelo Pellegrini ${ }^{* * * * *}$ \\ Morgana Secchi******
}

* Doutora e mestre em Agronegócios pela Universidade Federal do Rio Grande do Sul. Bacharela em Ciências Contábeis pela Universidade de Passo Fundo. Atualmente é professora titular da Faculdade de Ciências Econômicas, Administrativas e Contábeis e do Programa de Pós-Graduação em Administração da Universidade de Passo Fundo. E-mail: anapadilha@upf.br ORCID ID: https://orcid. org/0000-0002-0701-2640

** Doutora em Psicologia pela Pontifícia Universidade Católica do Rio Grande do Sul (2009). Mestra em Administração pela Universidade Federal de Santa Catarina (1999). Graduada em Psicologia pela Universidade de Passo Fundo (1983). Atualmente é professora na Universidade de Passo Fundo na Faculdade de Ciências Econômicas, Administrativas e Contábeis. E-mail: tatim@upf.br

**** Tecnólogo em Agronegócio pela Universidade de Passo Fundo. E-mail: edu.c.tres@gmail.com

**** Mestrando no Programa de Pós-Graduação em Administração da Universidade de Passo Fundo. Graduado no Curso Superior de Tecnologia em Agronegócio da Universidade de Passo Fundo. E-mail: 150087@upf.br ORCID ID: https://orcid.org/0000-0002-7548-8843

******* Mestranda no Programa de Pós-Graduação em Administração da Universidade de Passo Fundo. MBA em Administração Estratégia e Inovação de Negócios e bacharela em Administração pela Universidade de Passo Fundo. E-mail: 124166@upf.br ORCID ID: https://orcid.org/0000-0002-3239-7757

http://dx.doi.org/10.5335/rtee.v25i52.9877

Submissão: 04/09/2019. Aceite: 13/03/2020. 


\section{Resumo}

Nos últimos anos, a atenção voltou-se para as necessidades de desenvolvimento de tecnologias para a disposição de dejetos da suinocultura, uma vez que a atividade é caracterizada pela significativa carga de poluição e a criação está em constante expansão, visto que a carne suína representa quase a metade do consumo e da produção mundial de carnes, sendo considerada a principal fonte de proteína animal. Dessa forma, este estudo tem como objetivo apresentar o funcionamento de um sistema de fertirrigação com dejetos de suínos em uma propriedade rural. Em termos metodológicos, foi realizada uma pesquisa de levantamento de custos, comparando o sistema de fertirrigação por tanque tratorizado com o sistema de fertirrigação autopropelido. Os dados do estudo revelaram que a utilização dos dejetos como fertilizante é uma alternativa que se alinha à redução do impacto ambiental, especialmente por se configurar como nutriente para as culturas produzidas em propriedades que têm acesso a esse tipo de recurso de adubagem. Além disso, foi possível identificar nas simulações de custos em uma área que a fertirrigação se torna viável ao comparar seu custo com o identificado no sistema tratorizado.

Palavras-chave: Custos. Dejetos suínos. Fertirrigação.

\section{Introdução}

Sistemas de irrigação são comuns e muito importantes no cenário agrícola moderno, que é aperfeiçoado constantemente (MALASSIS, 1979). Com a criação do primeiro sistema de irrigação americano no ano de 1933 por Orton Englehart, que foi um cultivador de citrus residente no sul da Califórnia que inventou o primeiro aspersor de impacto em 1933 e revolucionou a história da produção de alimentos, iniciando uma nova era na irrigação mundial (GHERSI; BENCHARIF, 1992).

Com o intuito de utilizar a irrigação como forma de adubação, foi desenvolvido o sistema de fertirrigação, que, apesar de ser similar ao anterior, caracteriza-se por ser um pouco mais tecnológico e desenvolvido (MALASSIS, 1979). Segundo Pinto, Bassoi e Soares (2004), a fertirrigação é uma técnica de aplicação conjunta de fertilizantes e água, através de um sistema de irrigação. Essa técnica se torna ainda mais eficiente quando realizada com fertilizantes orgânicos, como, por exemplo, os dejetos oriundos da criação de suínos (SEGANFREDO; JUNIOR, 2008). No geral, é a forma mais comum em que o sistema é encontrado, principalmente em pequenas propriedades, onde é utilizado para fertirrigar áreas de pastagem destinadas à alimentação de vacas leiteiras, que são frequentes em estabelecimentos desse porte (CARDOSO, 2001). Os dejetos de suínos, em função de suas características químicas, têm um alto potencial fertilizante, podendo substituir em parte ou totalmente a adubação

Teoria e Evidência Econômica - a. 25, n. 52, p. 155-167, jan./jun. 2019 
química e contribuir significativamente para o aumento da produtividade das culturas e a redução dos custos de produção (SEGANFREDO; JUNIOR, 2008).

Portanto, o objetivo deste estudo é investigar custos envolvidos na implantação de um sistema de fertirrigação por aspersão em uma área de pastagem em uma pequena propriedade localizada no município de Constantina, no Rio Grande do Sul. Assim, o estudo se justifica devido ao crescente número de estabelecimentos agropecuários de pequeno porte que consorciam suas atividades de produção com suínos e gado leiteiro (SEGANFREDO; JUNIOR, 2008). Dessa forma, os dejetos de suínos são utilizados para a fertirrigação das pastagens da bovinocultura, uma vez que se apresentam como um recurso estratégico para a dieta das vacas leiteiras (MALASSIS, 1979).

\section{Contextualização do sistema de fertirrigação}

Em 2015, o Brasil foi o quarto maior produtor e exportador mundial de carne suína, produzindo um pouco mais de 3,5 milhões de toneladas, representando cerca de 3\% do total mundial (USDA, 2016). Em relação às exportações, o Brasil respondeu, no mesmo ano, por quase $9 \%$ do total mundial em volume, em participação na produção das quatro principais carnes. A produção brasileira de carne suína cresceu, no período de 2005 a 2015, 3,2\% a.a. (USDA, 2016).

A concentração regional da produção de carne suína está na Região Sul, responsável, em 2015, por $67 \%$ dos abates com algum tipo de fiscalização (IBGE, 2016). A Região Sudeste respondeu, no mesmo ano, por $18 \%$ e o Centro-Oeste, por 14\%. As Regiões Norte e Nordeste responderam pelo restante 1\%; entre os estados, destacaram-se Santa Catarina, com 27\% do total, Rio Grande do Sul e Paraná, com $20 \%$ cada (IBGE, 2016).

Segundo a Associação dos Criadores de Suínos do Rio Grande do Sul (ACSURS) (2017), no estado do Rio Grande do Sul foram abatidos 9.025.071 cabeças de suínos no ano de 2017, já suínos produzidos no estado e abatidos em outros somavam 925.058 cabeças, os quais eram destinados para os estados de Paraná, Santa Catarina e São Paulo, na grande maioria. No município de estudo, no ano de 2017, foram produzidas 64.207 cabeças de suínos, ficando na $40^{\circ}$ posição no ranking dos municípios gaúchos maiores produtores de suínos do estado (ACSURS, 2017).

Segundo a Embrapa (1998), um suíno produz diariamente, em média, durante o ciclo de 120 dias (período de engorda), 6,7 litros de dejetos líquidos. Vale ressaltar 
que, quando estiver em fase de crescimento, o animal produzirá menos, já quando estiver na fase adulta, produzirá mais. Nesse contexto, no município de estudo são produzidos anualmente mais de 51 milhões de litros/ano de dejetos líquidos de suínos, e em todo o estado do Rio Grande do Sul, esse valor passa dos 72 bilhões de litros/ano de dejetos (EMBRAPA, 1998).

O emprego de dejetos suínos nas propriedades suinícolas, de acordo com Konzen (2006), pode possibilitar o desenvolvimento de sistemas integrados de produção. Esses sistemas correspondem a um conjunto de alternativas produtivas que diversificam as fontes de renda, gerando maior estabilidade econômica e social. Deve-se deixar claro que essas alternativas produtivas devem ser desenvolvidas em conjunto, diferenciando, assim, os sistemas integrados da rotatividade de culturas (KONZEN, 2006).

O manejo dos dejetos é parte integrante de qualquer sistema produtivo de criação de animais e deve estar incluído no planejamento da construção de instalações suinícolas (KONZEN, 2006). Vale ressaltar que ele está incluso nas licenças de instalação e de operação, que são as licenças que autorizam a construção e a execução da atividade na propriedade (EMBRAPA, 1998). A seleção de um sistema de manejo é baseada em vários fatores, tais como o potencial de poluição dos dejetos, a necessidade de mão de obra, a área disponível, a operacionalidade do sistema, a legislação, a confiabilidade e os custos envolvidos (DARTORA; PERDOMO; TUMELERO, 1998).

\section{A utilização dos dejetos na fertilização}

Matos, Sediyama e Freitas (1997) argumentam que a suinocultura é uma atividade concentradora de dejetos com alta carga poluidora para solo, ar e água. Tendo em vista o desenvolvimento da criação de suínos e a organização da cadeia produtiva, a quantidade de dejetos originados da criação em grande escala no sistema de confinamento começa a chamar atenção de órgãos fiscalizadores pelo seu potencial poluidor, gerando desiquilíbrios ecológicos em razão da alta demanda bioquímica de oxigênio, cerca de 260 vezes superior à do esgoto doméstico (OLIVEIRA, 1993). Para Nogueira e Silva (2006), a quantidade total de dejetos líquidos produzidos varia de acordo com o desenvolvimento do peso dos animais. Para os suínos, os valores são decrescentes de $8,5 \%$ a $4,9 \%$ de seu peso vivo/dia, na faixa de $15 \mathrm{~kg}$ a $100 \mathrm{~kg}$ (NOGUEIRA; SILVA, 2006).

Uma maneira de evitar tais problemas é utilizar os dejetos para fertilização de lavouras ou pastagens (KONZEN, 2006). Esse processo inclui uma gama de 
alternativas de aplicação, observando as características dos sistemas para, a partir disso, escolher a melhor forma que se adapte à necessidade identificada (OLIVEIRA, 1993). Para Konzen (2006), as aplicações dos dejetos de suínos podem ser feitas com equipamento de aspersão e ou com tanques tratorizados.

Dessa forma, é possível identificar algumas vantagens de utilização de dejetos na fertilização do solo, tais como: a uniformização da temperatura, o aumento do poder tampão, a intensificação das atividades microbianas e enzimáticas (KIEHL, 1985; VIEIRA, 1997), a elevação dos teores de nitrogênio, potássio, fósforo, enxofre, cálcio e magnésio (DRUMOND, 2003), a melhoria da condutividade hidráulica e da capacidade de retenção de água, o aumento de porosidade e a redução da densidade (DRUMOND, 2003), a alteração das propriedades biológicas que servem como fonte de alimento para os microrganismos heterotróficos (CARDOSO, 2001), o aumento do teor de matéria seca em pastagem (KONZEN, 2002).

Quando os dejetos de suínos são incorporados, ocorre uma estimulação da atividade microbiana, sendo que as exigências de oxigênio por esses microrganismos superam a taxa de difusão do oxigênio atmosférico (VIEIRA, 1997). Assim, tornam o ambiente anaeróbico, ao passo que a degradação da matéria orgânica não se completa, provocando redução no PH do solo e produção de gases malcheirosos (DRUMOND, 2003). Se a taxa de mineralização do material orgânico for reduzida, os nitratos são convertidos em nitrogênio elementar e óxido nitroso pelo processo de denitrificação (VIEIRA, 1997).

\section{Fertirrigação}

Segundo Dalpizol (2016), a cada dia, o produtor busca aliar ações para elevar os ganhos no campo, uma técnica prática, que cada vez ganha mais espaço, é a fertirrigação.

As aplicações dos dejetos de suínos podem ser feitas com equipamento de aspersão e ou com tanques tratorizados. O investimento para o uso dos tanques é relativamente alto, há limitação de área possível de adubar, tanto em quantidade quanto em topografia, e ainda existe o risco de compactação excessiva do solo. Os tanques tratorizados permitem, por outro lado, fazer a distribuição uniforme e/ou localizada no solo. Os sistemas de aspersão permitem a distribuição apenas de maneira uniforme, porém, com a vantagem de ser mais precisa em sua quantificação, permitindo também maior área fertilizada com o mesmo investimento em equipamentos (KONZEN, 2006, p. 14).

Os resultados de produtividade em áreas de pastagens com a utilização do sistema de fertirrigação por aspersão são muito interessantes, pois um estudo feito 
anteriormente possibilitou a produção de $5.928 \mathrm{~kg} / \mathrm{ha}-1$ de matéria seca em períodos de corte a cada 35 dias, o que seria um número elevado comparado sem a fertirrigação (KONZEN, 2006). Além do aumento da produtividade, a qualidade das pastagens também é afetada, expressando bons resultados (KONZEN, 2006). Em estudos realizados com Brachiaria brizantha cv. Marandu, houve um incremento de $156 \%$ na produção de matéria seca/ha, melhorando a qualidade da proteína na matéria seca em 230\% (KONZEN, 2006).

\section{Custos na fertirrigação}

De acordo com Martins (1998), os custos são basicamente divididos em diretos, que possuem alguma medida de consumo na produção, e indiretos, que não podem ser mensurados de forma exata, mas estão relacionados à produção. Konzen (2006) afirma que o custo da fertilização por aspersão, normalmente, é 50\% menor do que comparado com a fertilização com tanque tratorizado, além de não oferecer restrições de trânsito de acordo com as áreas.

Estudo de custos da aplicação de dejetos feito em Santa Catarina, pela Epagri e Embrapa Suínos e Aves, compara os sistemas de aplicação com tanque tratorizado e aspersão. Avaliaram-se os dois sistemas, com a dose anual de $40 \mathrm{~m} 3$ ha-1, em áreas que variaram de seis a 60 hectares. $\mathrm{O}$ estudo mostra que, até 24 hectares adubados, os custos de ambos se equipararam. À medida que a área fertilizada cresceu, os custos da aspersão decresceram $52,6 \%$ em relação ao tanque tratorizado (KONZEN, 2006, p. 20).

Tais questões podem ser mensuradas a partir do levantamento de custos de cada projeto pretendido, já que cada unidade produtiva possui peculiaridades no que diz respeito aos aspectos facilitadores e limitadores (MARTINS, 1998). A próxima seção dedica-se à apresentação dos procedimentos metodológicos que sustentam o alcance do objetivo delimitado.

\section{Procedimentos metodológicos}

Para alcançar o objetivo do estudo, investigar os custos envolvidos na implantação de um sistema de fertirrigação por aspersão em uma área de pastagem em uma pequena propriedade localizada no município de Constantina, RS, foi realizada uma pesquisa quantitativa, do tipo estudo de caso, sendo a unidade de análise uma pequena propriedade produtora de suínos.

Teoria e Evidência Econômica - a. 25, n. 52, p. 155-167, jan./jun. 2019 
A pesquisa contou com o uso de fontes de dados primários e secundários. Os dados primários foram coletados juntamente com três produtores rurais que atuam na produção suinícola, incluindo, também, os dados relacionados às características da propriedade rural, aos custos de implantação dos dois sistemas e, também, aos custos de funcionamento e manutenção, os quais auxiliaram na compreensão da capacidade e do dimensionamento de cada sistema avaliado, o que possibilitou a comparação entre ambos. Quanto aos dados secundários, eles foram coletados em três empresas que comercializam e instalam equipamentos para a fertirrigação.

De posse dos dados, a próxima etapa centrou-se na análise, que foi desenvolvida por meio do software Microsoft Excel. Os dados foram dispostos em planilhas previamente configuradas de acordo com os dois sistemas de fertirrigação, dividindo os custos inerentes a cada sistema analisado.

\section{Resultados e discussões}

A propriedade estudada localiza-se na zona rural do município de Constantina, no estado do Rio Grande do Sul, possui 90ha de área, sendo que 10ha são destinados à produção de pastagens e silagens, 75 ha são destinados à produção de grãos, como soja, milho e trigo, e 5ha são destinados às instalações e à residência. A propriedade possui o sistema vertical terminador, em que são produzidos 1.000 suínos a cada 4 meses, integrado a uma empresa, e possui ainda 23 vacas em lactação, com o leite sendo vendido para uma cooperativa.

A partir do objetivo delimitado na pesquisa, concentrou-se na comparação dos custos envolvidos nos dois sistemas de fertirrigação. A primeira análise apresenta os custos relacionados aos sistemas de tanque tratorizado (Tabela 1). 
Tabela 1 - Sistema de tanque tratorizado

\begin{tabular}{|c|c|c|c|c|c|}
\hline $\begin{array}{l}\text { Máquinas/ } \\
\text { Implementos }\end{array}$ & $\begin{array}{l}\text { Valor de novo } \\
\text { (VN) }\end{array}$ & $\begin{array}{l}\text { Vida útil } \\
\text { (horas) }\end{array}$ & $\begin{array}{l}\text { Valor residual } \\
\qquad(\% \mathrm{VN})\end{array}$ & $\begin{array}{c}\text { Valor } \\
\text { depreciado } \\
(\% \text { VN) }\end{array}$ & $\begin{array}{c}\text { Valor } \\
\text { depreciado } \\
\text { (R\$) }\end{array}$ \\
\hline Trator $78 \mathrm{cvs}$ & $\mathrm{R} \$ 120.000,00$ & 10.000 & $50 \%$ & $50 \%$ & $\mathrm{R} \$ 60.000,00$ \\
\hline $\begin{array}{l}\text { Tanque } 5.000 \\
\text { litros }\end{array}$ & $\mathrm{R} \$ 25.000,00$ & 2.500 & $40 \%$ & $60 \%$ & $\mathrm{R} \$ 15.000,00$ \\
\hline $\begin{array}{c}\text { Custo por hora/ } \\
\text { Trator } 78 \mathrm{cvs}\end{array}$ & $\begin{array}{l}\text { Quantidade } \\
\text { do produto }\end{array}$ & $\begin{array}{l}\text { Número } \\
\text { de horas }\end{array}$ & $\begin{array}{c}\text { Quantidade/ } \\
\text { hs }\end{array}$ & Valor unitário & Valor total \\
\hline Combustível & 7 & 1 & 7 & $\mathrm{R} \$ 3,77$ & $\mathrm{R} \$ 26,39$ \\
\hline \multicolumn{6}{|l|}{ Lubrificantes } \\
\hline Óleo motor & 13 & 250 & 0,052 & $\mathrm{R} \$ 15,80$ & $\mathrm{R} \$ 0,82$ \\
\hline Óleo transmissão & 40 & 1500 & 0,02666667 & $\mathrm{R} \$ 29,99$ & $\mathrm{R} \$ 0,80$ \\
\hline $\begin{array}{l}\text { Reduções e } \\
\text { tração }\end{array}$ & 4,5 & 250 & 0,018 & $\mathrm{R} \$ 21,50$ & $\mathrm{R} \$ 0,39$ \\
\hline Graxa & 0,5 & 50 & 0,01 & $\mathrm{R} \$ 25,95$ & $\mathrm{R} \$ 0,26$ \\
\hline \multicolumn{6}{|l|}{ Pneus } \\
\hline Dianteiros & 2 & 2.000 & 0,001 & $\mathrm{R} \$ 1.310,00$ & $\mathrm{R} \$ 1,31$ \\
\hline Traseiros & 2 & 2.500 & 0,0008 & $\mathrm{R} \$ 2.890,00$ & $\mathrm{R} \$ 2,31$ \\
\hline Peças e serviços & 1 & 1.000 & 0,001 & $\mathrm{R} \$ 500,00$ & $\mathrm{R} \$ 0,50$ \\
\hline Depreciação & 1 & 10.000 & 1,00000E-04 & $\mathrm{R} \$ 60.000,00$ & $\mathrm{R} \$ 6,00$ \\
\hline & & & & $\begin{array}{l}\text { Custo total por } \\
\text { hora }\end{array}$ & $\mathrm{R} \$ 38,78$ \\
\hline $\begin{array}{l}\text { Distribuidor } \\
5.000 \text { litros }\end{array}$ & $\begin{array}{l}\text { Quantidade } \\
\text { do produto }\end{array}$ & $\begin{array}{l}\text { Número } \\
\text { de horas }\end{array}$ & $\begin{array}{c}\text { Quantidade/ } \\
\text { hs }\end{array}$ & Valor unitário & Valor total \\
\hline Pneus & 4 & 500 & 0,008 & $\mathrm{R} \$ 489,00$ & $\mathrm{R} \$ 3,91$ \\
\hline \multicolumn{6}{|l|}{ Lubrificantes } \\
\hline $\begin{array}{l}\text { Óleo caixa de } \\
\text { engrenagens }\end{array}$ & 1 & 250 & 0,004 & $\mathrm{R} \$ 21,50$ & $\mathrm{R} \$ 0,09$ \\
\hline $\begin{array}{l}\text { Óleo bomba } \\
\text { vácuo }\end{array}$ & 1 & 10 & 0,1 & $\mathrm{R} \$ 15,80$ & $\mathrm{R} \$ 1,58$ \\
\hline $\begin{array}{l}\text { Óleo para } \\
\text { pulverização }\end{array}$ & 1 & 10 & 0,1 & $\mathrm{R} \$ 15,80$ & $\mathrm{R} \$ 1,58$ \\
\hline Graxa & 0,5 & 10 & 0,05 & $\mathrm{R} \$ 25,00$ & $\mathrm{R} \$ 1,25$ \\
\hline Peças e serviços & 1 & 100 & 0,01 & $\mathrm{R} \$ 200,00$ & $\mathrm{R} \$ 2,00$ \\
\hline \multirow[t]{2}{*}{ Depreciação } & 1 & 2.500 & 0,0004 & $\mathrm{R} \$ 15.000,00$ & $\mathrm{R} \$ 6,00$ \\
\hline & & & & $\begin{array}{l}\text { Custo total por } \\
\text { hora }\end{array}$ & $\mathrm{R} \$ 12,50$ \\
\hline
\end{tabular}

\section{Custo total/hora do conjunto}

\begin{tabular}{l|l}
\hline Trator & $\mathrm{R} \$ 38,78$ \\
\hline Distribuidor & $\mathrm{R} \$ 12,50$ \\
\hline Total & $\mathbf{R} \$ \mathbf{5 1 , 8 0}$ \\
\hline
\end{tabular}

Fonte: dados da pesquisa, 2019. 
Os custos do sistema tratorizado foram separados por hora do trator e por hora do tanque distribuidor, levando-se em consideração que o trator possui como características 78 cvs de potência e um distribuidor de 5.000 litros. Como isso, foi possível detalhar os dados de cada equipamento, sendo o custo/hora do trator $\mathrm{R} \$ 38,78$ e, do tanque distribuidor, $\mathrm{R} \$ 12,50$. Nesse sentido, calculou-se que o custo total/hora desses dois equipamentos alcançou o montante de R $\$ 51,28 /$ hora. Já a Tabela 2 apresenta os custos específicos do sistema autopropelido.

Tabela 2 - Sistema autopropelido

\begin{tabular}{l|r|r|r|r|r}
\hline $\begin{array}{c}\text { Sistema } \\
\text { autopropelido }\end{array}$ & $\begin{array}{c}\text { Valor de } \\
\text { novo (VN) }\end{array}$ & $\begin{array}{c}\text { Vida útil } \\
\text { (Horas) }\end{array}$ & $\begin{array}{c}\text { Valor residual } \\
\text { (\%doVN) }\end{array}$ & $\begin{array}{c}\text { Valor } \\
\text { depreciado } \\
\text { (\%VN) }\end{array}$ & $\begin{array}{c}\text { Valor } \\
\text { depreciado } \\
\text { (R\$) }\end{array}$ \\
\hline Fertirrigação/5ha & $\mathrm{R} \$ 38.500,00$ & 3000 & $40 \%$ & $60 \%$ & $\mathrm{R} \$ 23.100,00$ \\
\hline $\begin{array}{c}\text { Custo por hora } \\
\text { Fertirrigação }\end{array}$ & $\begin{array}{c}\text { Quantidade } \\
\text { do produto }\end{array}$ & $\begin{array}{c}\text { Número } \\
\text { de horas }\end{array}$ & $\begin{array}{c}\text { Quantidade/ } \\
\text { hs }\end{array}$ & Valor unitário & Valor total \\
\hline Combustível & 4 & 1 & 4 & $\mathrm{R} \$ 3,70$ & $\mathrm{R} \$ 14,80$ \\
\hline Óleo motor & 5 & 250 & 0,02 & $\mathrm{R} \$ 15,80$ & $\mathrm{R} \$ 0,32$ \\
\hline Peças e serviços & 1 & 100 & 0,01 & $\mathrm{R} \$ 500,00$ & $\mathrm{R} \$ 5,00$ \\
\hline Depreciação & 1 & 3000 & 0,000333333 & $\mathrm{R} \$ 23.100,00$ & $\mathrm{R} \$ 7,70$ \\
\hline
\end{tabular}

Fonte: dados da pesquisa, 2019.

A Tabela 2 apresenta os custos operacionais do sistema de fertirrigação autopropelido para uma área de 5 ha, acionado por motor a combustão, com capacidade de bombeamento simultâneo para 6 aspersores. Nota-se que esse sistema apresenta um baixo custo operacional e de manutenção na ordem de $R \$ 27,50 /$ hora, considerando uma área de 5ha. Ressalta-se que o custo pode reduzir ao longo do tempo, ao considerar a ampliação da área de implantação, uma vez que o motor, os aspersores e a bomba que o sistema utiliza possuem capacidade de fertirrigação de uma área de até 15 ha. Portanto, salienta-se que o único custo a ser considerado, caracterizado como variável, seria o relacionado à tubulação.

Outro fator considerado na análise desse sistema foi a capacidade de campo de cada sistema, o que auxiliou na identificação do custo efetivo de aplicação de acordo com a quantidade possível de ser fertirrigada por hora. Assim, foi possível calcular a capacidade de campo dos dois sistemas:
a) sistema de tanque tratorizado: $20.000 \mathrm{~L} / \mathrm{hora}$
b) sistema autopropelido: $60.000 \mathrm{~L} / \mathrm{hora}$ 
Dessa forma, devido à disposição dos custos calculados nos dois sistemas (Tabelas 1 e 2), o custo/hora do sistema tratorizado é muito maior, o dobro do sistema autopropelido. Não somente isso, a capacidade de campo do sistema tratorizado é de 1/3 da capacidade do sistema autopropelido, o que o torna ainda mais caro.

Para fins prospectivos, por exemplo, se uma área de 5ha necessitar de uma fertirrigação de $20.000 \mathrm{~L} /$ ha, com o sistema tratorizado seriam necessárias 5 horas de trabalho, o que resultaria em um custo de $\mathrm{R} \$ 256,40$. Na análise do sistema autopropelido, seria necessária 1,66 hora de trabalho, gerando um custo de $\mathrm{R} \$ 46,65$, um valor em torno de cinco vezes menor que o do sistema tratorizado.

\section{Conclusões}

Após a apresentação dos resultados obtidos, foi possível identificar a vantagem de adoção do sistema autopropelido em relação ao sistema tratorizado, justificada pelo desempenho apresentado quando se comparam os custos envolvidos nos dois sistemas. Além disso, é importante destacar o impacto envolvido na redução de custos da produção agrícola, seja uma área de pastagem ou de produção de grãos. Dessa forma, além dos custos, vários outros fatores promovem vantagens por meio da adoção do sistema autopropelido, tais como o ganho de tempo, a redução da fadiga de quem realiza a atividade, bem como se evita a compactação do solo, que, no sistema tratorizado, é um aspecto que o produtor rural não pode evitar, uma condição que, muitas vezes, passa despercebida.

Sendo assim, os resultados obtidos neste estudo podem auxiliar na tomada de decisão dos produtores rurais que desenvolvem atividades agropecuárias que podem valer-se desse tipo de opção de fertirrigação. Não somente isso, são oferecidos insigths que, apesar de resumidos, podem ser aperfeiçoados ao longo do tempo, podendo ser incluídas ou suprimidas variáveis relacionadas aos custos a partir das inovações que surgem no contexto das atividades de produção para o agronegócio.

Portanto, conclui-se que a diferença de custos identificada nas duas análises é um elemento a ser considerado na dimensão de elaboração de projetos de viabilidade econômica e financeira. Percebe-se que ambos os investimentos contribuem para a adoção, não deixando de considerar o contexto de análise. Para trabalhos futuros, sugere-se que seja feita uma pesquisa com mais propriedades que utilizam esses sistemas, a fim de aprimorar as análises. 


\title{
Fertirrigation with swine waste: a cost analysis of the self-propelled system $\mathrm{x}$ tractor system
}

\begin{abstract}
In recent years, attention has been focused on the need to develop technologies for the disposal of swine manure, since the activity is characterized by a significant pollution load and the breeding is constantly expanding, since the meat pigmeat represents almost half of world meat consumption and production and is considered the main source of animal protein. Thus, the study aims to present the operation of a fertirrigation system with swine manure on a rural property. In methodological terms, a survey of costs was carried out, comparing the fertigation system by the tractor tank with the self-propelled fertirrigation system. The study data show that the use of the waste as fertilizer is an alternative that aligns with the reduction of environmental impact, especially as it is configured as a nutrient for the crops produced in properties that have access to this type of fertilization resource. Moreover, it was possible to identify in the cost simulations in one area, that the fertigation becomes viable when comparing the cost with that identified in the tratorized system.
\end{abstract}

Keywords: Costs. Dejects swine. Fertigation.

\section{Fertigación de desechos porcinos: un análisis de costos del sistema autopropulsado $\mathrm{x}$ sistema de tractor}

\section{Resumen}

En los últimos años, la atención se ha centrado en las necesidades para el desarrollo de tecnologías para la eliminación del estiércol porcino, ya que la actividad se caracteriza por una carga de contaminación significativa y la creación se expande constantemente, ya que la carne la carne de cerdo representa casi la mitad del consumo y producción de carne del mundo, siendo considerada la principal fuente de proteína animal. Por lo tanto, el estudio tiene como objetivo presentar el funcionamiento de un sistema de fertirrigación con estiércol porcino en una propiedad rural. En términos metodológicos, se realizó una encuesta de costos, comparando el sistema de fertirrigación de un tanque tractor con el sistema de fertirrigación autopropulsado. Los datos del estudio muestran que el uso del estiércol como fertilizante se revela como una alternativa que está alineada con la reducción del impacto ambiental, especialmente porque está configurado como un nutriente para cultivos producidos en propiedades que tienen acceso a este tipo de recurso fertilizante. Además, fue posible identificar en las simulaciones de costos en un área, que la fertirrigación se vuelve viable al comparar el costo con el identificado en el sistema del tractor.

Palabras clave: Costos. Estiércol porcino. Fertirrigación. 


\section{Referências}

ACSURS. ASSOCIAÇÃO DOS CRIADORES DE SUÍNOS DO RIO GRANDE DO SUL. Abates no Rio Grande do Sul. 2017. Disponível em: http:/www.regiaodosvales.com.br/wp-content/ uploads/2018/03/Abate-Su\%C3\%ADnos-2017-Acsurs-atualizada-27-02-2018-1.pdf. Acesso em: 17 jul. 2019.

CARDOSO, J. L. Política de financiamento rural: antecedentes e perspectivas. Campinas: Feagri/Unicamp, 2001.

DALPIZOL, E. Você sabe o que é fertirrigação? 2016. Disponível em: https://blogs.canalrural.uol. com.br/gaf/2016/03/21/81/. Acesso em: 04 maio 2019.

DARTORA, V.; PERDOMO, C. C.; TUMELERO, I. L. Manejo de dejetos de suínos. Boletim Informativo de Pesquisa e Extensão, v. 7, n. 11, 1998.

DRUMOND, L. C. D. Aplicação de água residuária de suinocultura por aspersão em malha: desempenho hidráulico do sistema e produção de capim Tifton 85. 2003. 120 f. Tese (Doutorado em Produção Vegetal) - Faculdade de Ciências Agrárias e Veterinárias, Universidade Estadual Paulista "Julio de Mesquita Filho", Jaboticabal, 2003.

EMBRAPA - EMPRESA BRASILEIRA DE PESQUISA AGROPECUÁRIA. Composição média dos dejetos suínos com matéria seca de 1,94\%. Boletim informativo Pesquisa Suínos e Aves / Extensão, Porto Alegre, Emater, RS, ano 07, n. 11, 1998.

GHERSI, G.; BENCHARIF, H. Iniciação à economia agroalimentar. Paris: HATIER-AUPELF, 1992.

IBGE - INSTITUTO BRASILEIRO DE GEOGRAFIA E ESTATÍSTICA. Séries históricas. 2016. Disponível em: https://ww2.ibge.gov.br/home/estatistica/indicadores/agropecuaria/producaoagropecuaria/teabat12002.shtm. Acesso em: 17 jul. 2019.

KIEHL, E. J. Fertilizantes orgânicos. São Paulo: Agronômica Ceres, 1985.

KONZEN, E. A. Aproveitamento do adubo líquido da suinocultura na produção agropecuária. In: CONGRESSO NACIONAL DE IRRIGAÇÃO E DRENAGEM, 2002. Anais [...]. Uberlândia: ABID, 2002.

KONZEN, E. A. Viabilidade Ambiental e Econômica de Dejetos de Suínos. Sete Lagoas: Embrapa Milho e Sorgo, 2006.

MALASSIS, L. Economie agro-alimentaire: économie de la consommation et de la production agro-alimentaire. Paris: Cujas, 1979.

MARTINS, E. Contabilidade de custos. 6. ed. São Paulo: Atlas, 1998.

MATOS, A. T. de; SEDIYAMA, M. A. N.; FREITAS, S. P. Características químicas e microbiológicas do solo, influenciadas pela aplicação de dejeto líquido de suínos. Revista Ceres, Viçosa, v. 44, n. $254,1997$.

NOGUEIRA, C.; SILVA, I. Aplicação de águas residuárias de suinocultura na irrigação. Thesis, São Paulo, ano III, v. 6, p. 18-29, $2^{\circ}$ semestre 2006.

OLIVEIRA, P. A. V. Manual de manejo e utilização dos dejetos de suínos. Concórdia: Embrapa-CNPSA, 1993. 
PINTO, J. M.; BASSOI, L. H.; SOARES, J. M. Manejo da fertirrigação. 2004. Disponível em: https://www.agencia.cnptia.embrapa.br/Agencia22/AG01/arvore/AG01_53_24112005115222.html. Acesso em: 10 abr. 2019.

SEGANFREDO, M. A.; JUNIOR, V. Dejetos suínos: adubo ou poluente. 2008. Disponível em: http://www.cnpsa.embrapa.br/down.php?tipo=artigos\&cod_artigo=210. Acesso em: 27 mar. 2019. USDA - UNITED STATES DEPARTMENT OF AGRICULTURE. Livestock and Poultry: World Markets and Trade. Foreign Agricultural Service, 12 out. 2016. Disponível em: https:/ / apps.fas. usda.gov/psdonline/circulars / livestock_poultry.pdf. Acesso em: 4 jun. 2019.

VIEIRA, L. Produção de minhocas em dejetos suínos estabilizados e valor nutritivo da farinha de minhoca para suínos. 1997. 56 f. Dissertação (Mestrado em Zootecnia) - Universidade Federal de Viçosa, Viçosa, 1997. 